\title{
Mobile Phone Operations using Human Eyes Only and its Applications
}

\author{
Kohei Arai \\ Information Science Department \\ Graduate School of Science and Engineering, Saga University \\ Saga City, Japan
}

\begin{abstract}
Mobile phone operations using human eyes only is proposed together with its applications for cooking with referring to recipes and manufacturing with referring to manuals, production procedure, so on. It is found that most of mobile phone operations can be done without touching the screen of the mobile phone. Also, mobile phone operation success rate based on the proposed method is evaluated for the environmental illumination conditions, visible or near infrared (NIR) cameras, the distance between user and mobile phone, as well as pupil size detection accuracy against the environmental illumination changes. Meanwhile, the functionality of two typical applications of the proposed method is confirmed successfully.
\end{abstract}

Keywords-Mobile phone operations; line of sight estimation; gaze estimation; wearable computing; pupil detection

\section{INTRODUCTION}

Evaluation of users' impact for using the proposed Eye Based Human-Computer Interaction: EBHCI with moving and fixed keyboard by using EEG signals is investigated [1]. Electric wheel chair controlled by human eyes only with obstacle avoidance is proposed [2]. Robot arm control with human eyes only and its application to help having meal for patients is proposed [3]. These methods and systems are overviewed (Human-Computer Interaction with human eyes only and its applications) [4].

A new keyboard for improving accuracy and minimizing fatigue effect is invented [5] followed by moving keyboard for EBHCI [6]. Service robot which is controlled by human eyes only with voice communication capability is developed as an example of EBHCI [7] followed by eye-based domestic robot allowing patient to be self-services and communications remotely [8].

Method for psychological status estimation by gaze location monitoring using EBHCI is proposed [9] followed by method for psychological status monitoring with line of sight vector changes (Human eyes movements) detected with wearing glass [10]. It becomes wearable computing system with input output devices based on EBHCI allowing location based web services [11].

Speed and vibration performance as well as obstacle avoidance performance of electric wheel chair controlled by human eyes only is evaluated [12]. Service robot with communication aid together with routing controlled by human eyes is overviewed [13]. On the other hand, information collection service system by human eyes for disable persons is developed [14]. Meanwhile, the relation between psychological status and eye movement is clarified [15].

Method for 3D image representation with reducing the number of frames based on characteristics of human eyes is proposed [16]. On the other hand, error analysis of line of sight estimation using Purkinje images for EBHCI is made [17]. Then, new service robot controlled by human eye which allows patients in hospitals self-services remotely is overviewed [18].

In the paper, mobile phone operations using human eyes only is proposed together with its applications for cocking with referring to recipes and manufacturing with referring to manuals, production procedure, so on. Although EBHCI is computer based method and systems, the proposed system EBHCI can be realized with mobile phone. Without touching the screen of the mobile phone, some of the operations can be done with human eyes only.

The following section describes the proposed system. Then, experiments are described with some experimental results of the mobile operation success rate followed by some applications of the proposed system. Finally, conclusion is described with some discussions.

\section{PROPOSED SYSTEM}

\section{A. Proposed Methods}

Fig. 1 shows the proposed gaze estimation procedure. With Near Infrared: NIR camera, face image is acquired followed by face detection by using OpenCV. Then, eye detection is made with OpenCV followed by pupil detection with ellipsoidal shape approximation. Also, Purkinje image which is acquired with six NIR Light Emission Diodes: LEDs are used for estimation of cornea curvature and curvature center.

Example of the acquired Purkinje image (Red ellipsoid) and pupil (Blue ellipsoid) of which the shape is approximated with ellipsoid is shown in Fig. 2(a). The Purkinje images are aligned with ellipsoidal shape because the reflected light of six LEDs at the surface of the eye is aligned with the hexagonal shape as is shown in Fig. 2(b). The line of sight is defined as the line on the curvature center and pupil center. Using the estimated line of sight, gaze location is estimated. It, however, is not stable enough during the period of the gaze estimation, every $0.5 \mathrm{sec}$. It is shorter than $0.3 \mathrm{sec}$. for typical accidental blink time. Therefore, it is intentional blink if user close their 
eye for much longer than $0.3 \mathrm{sec}$. Thus, the line of sight can be estimated every $0.5 \mathrm{sec}$.

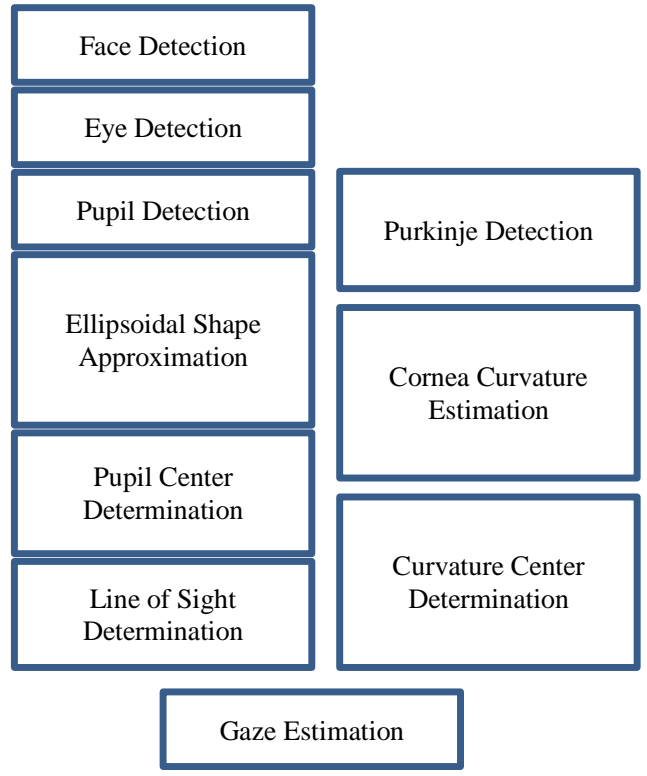

Fig. 1. Procedure of the proposed gaze estimation.

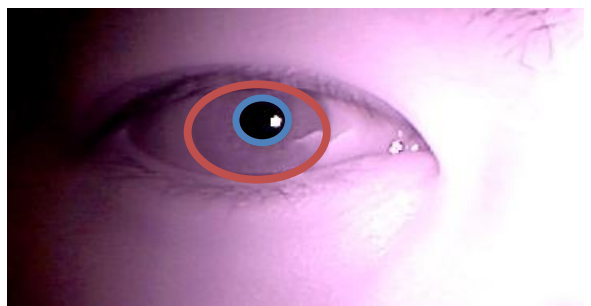

(a) Purkinje image

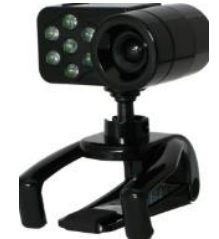

(b) NIR camera used

Fig. 2. Example of Purkinje image (red ellipsoid) and pupil of which the shape is approximated with ellipsoid (blue ellipsoid) and NIR camera used.

Pupil detection procedure is illustrated in Fig. 3. The acquired eye image is binarized first, then edge is detected with Canny filter. After that, ellipsoidal shapes are selected from the edge images as candidates of the pupil. Then, the shorter and the longer radius is estimated followed by pupil center determination of which the two radius are crossing at the pupil center.

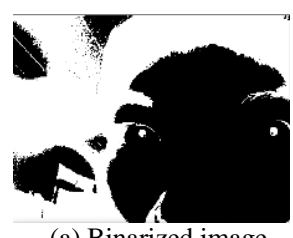

(a) Binarized image

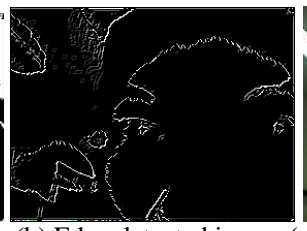

(b) Edge detected image (c) Pupil detected image
Fig. 3. Pupil detection method.

\section{B. Mobile Phone Operation Selection}

Fig. 4 shows the designed four mobile phone operations with the estimated gaze location and blinks. Due to the fact that line of sight estimation cannot be made accurately and stable, just four operations can be detected with the estimated line of sights. These four operations would be enough for choosing the required operations of the applications of the proposed method.

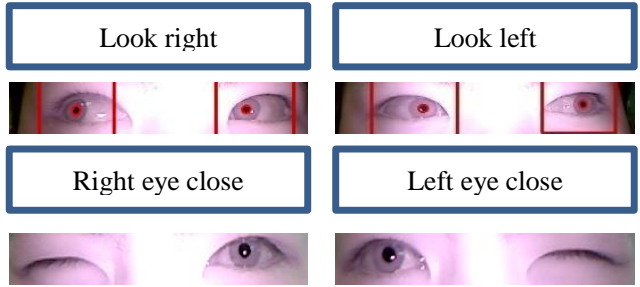

Fig. 4. Four mobile phone operations with the estimated gaze location and blinks.

It, however, is still difficult to identify the direction of which user is looking to. Therefore, the proposed method defines the direction by using the difference between the estimated eye center and pupil center. It is relatively easy to find the eye center because the two ends of eye can be identified using acquired eye images.

Fig. 5 shows the estimated gaze location when user is looking to up and down directions as well as right and left directions. It is relatively easy to discriminate for to right and left directions while it is not so easy to discriminate for up and down directions. Therefore, just the discrimination of right and left directions is used.

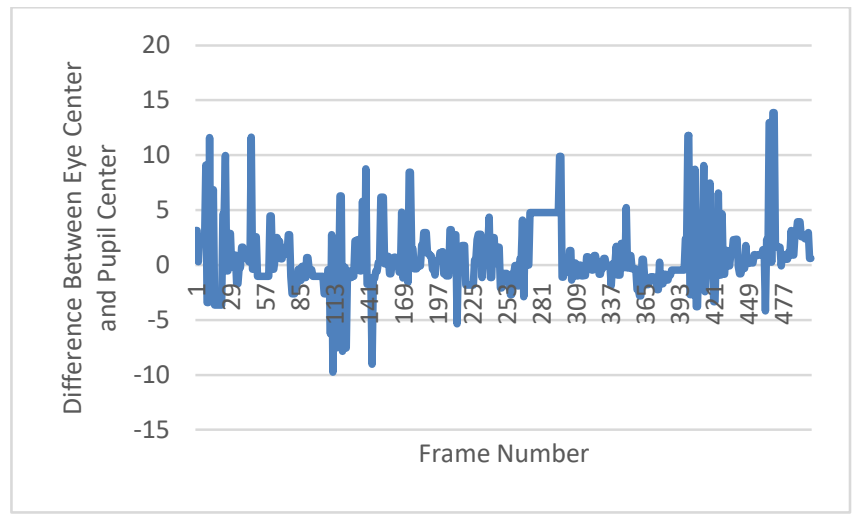

(a) Upward

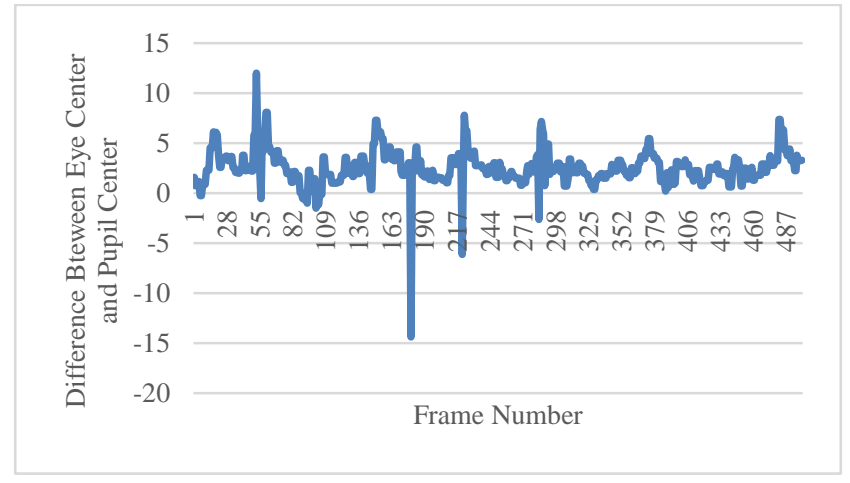

(b) Downward 


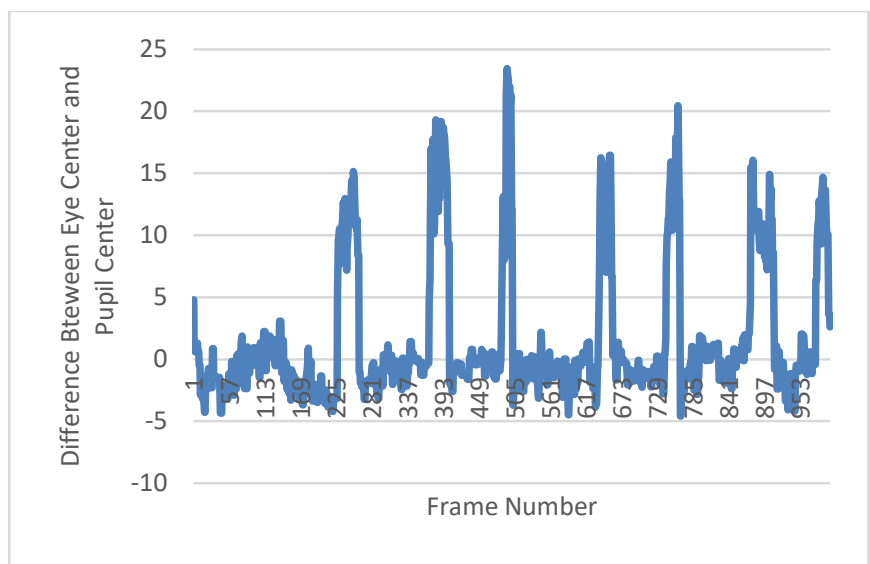

(c) Rightward

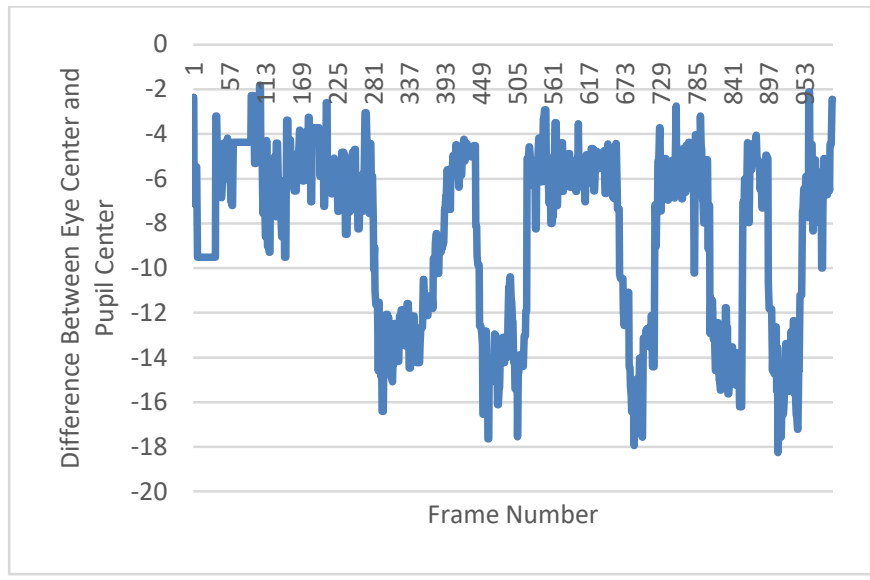

(d) Leftward

Fig. 5. Estimated gaze location when user is looking to up and down directions as well as right and left directions.

\section{EXPERIMENT}

\section{A. Experimental Configuration}

Fig. 6(a) shows the experimental configuration. The distance between user and NIR camera and LED is set at 15, 20, 25 , and $30 \mathrm{~cm}$. Illuminations are set at three conditions, 40 to 50 Lux, 140 to 150 Lux. On the other hand, Fig. 6(b) shows the outlook of the experimental configuration.

\section{$15,20,25,30 \mathrm{~cm}$}

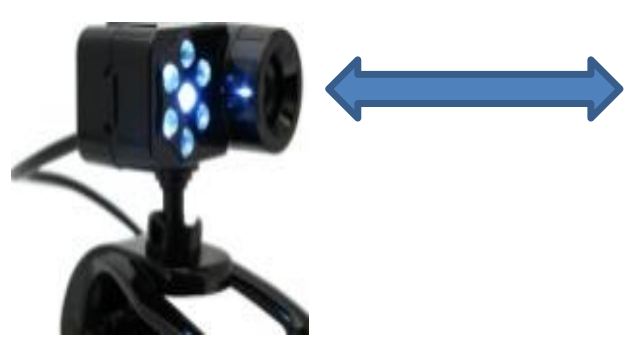

(a) Experimental configuration

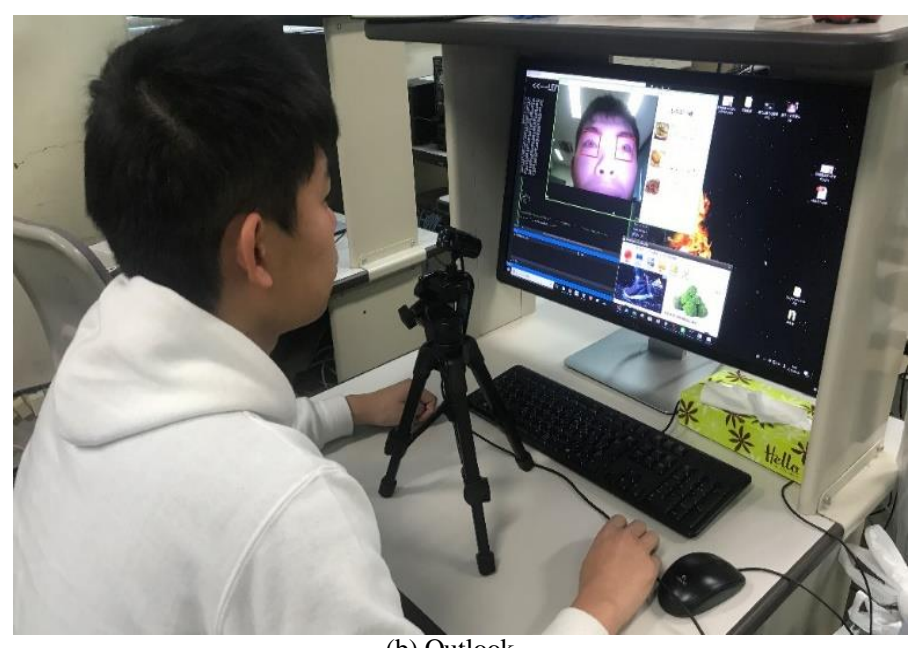

(b) Outlook

Fig. 6. Experimental configuration.

\section{B. Threshold Determination using Standard Deviation of the Difference between Eye Center and Pupil Center}

Meanwhile, Fig. 7 shows the difference between eye center and pupil center of right and left eyes when user is looking to right and left directions. In the figure, average and standard deviation of the difference between eye center and pupil center are also shown with the black bars. It is relatively easy to discriminate the direction of which user is looking to. Thus, the direction of which user is looking to can be detected.

As shown in Fig. 7(a) and (b), it can be decided that the user is now looking to the left direction because the difference between eye center and pupil center is lower than the standard deviation for a while. Meanwhile, it also can be recognized the user is now looking to the right direction because the difference is larger than the standard deviation for a while as shown in Fig. 7(c) and (d).

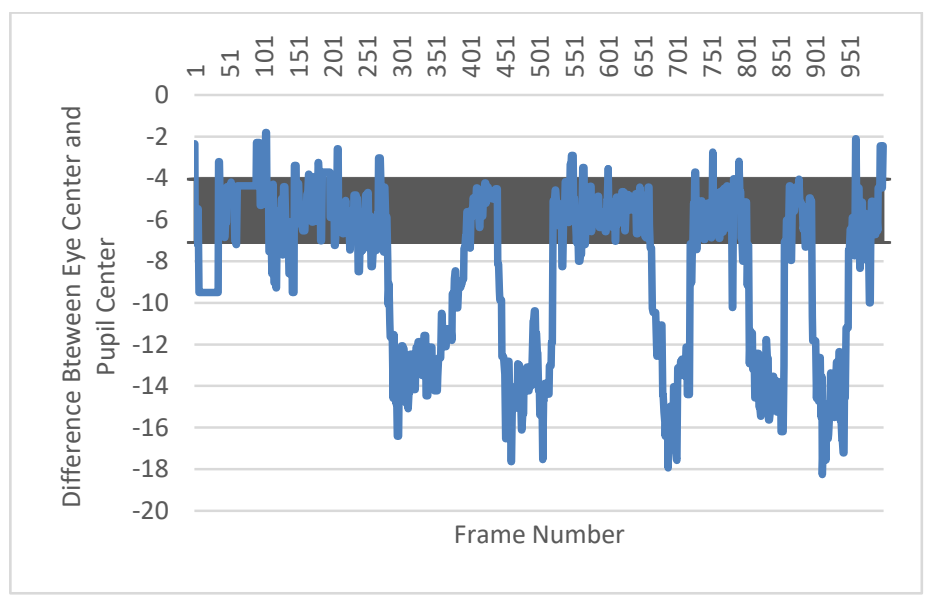

(a) Looking to left, Right eye 


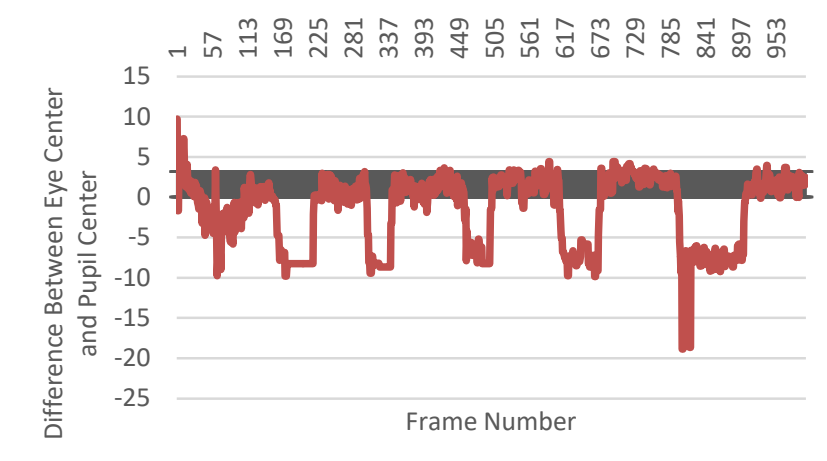

(b) Looking to left, Left eye

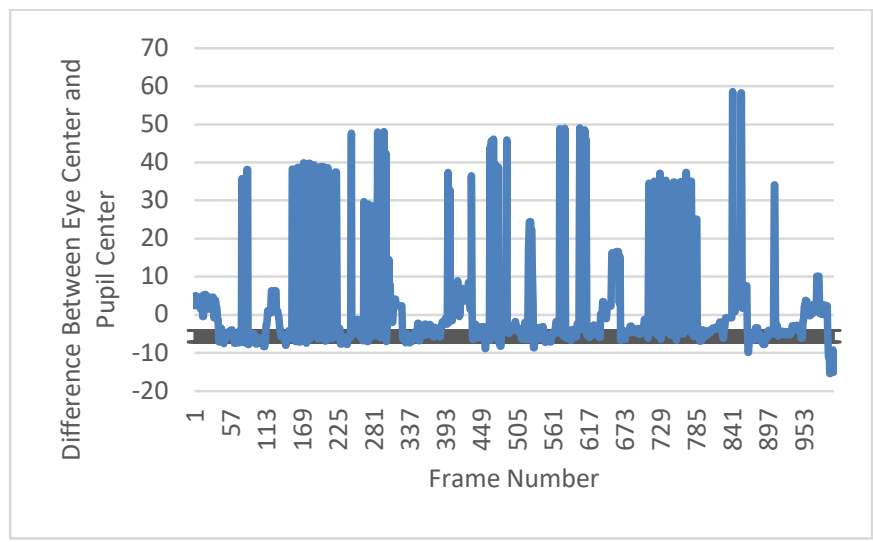

(c) Looking to right, Right eye

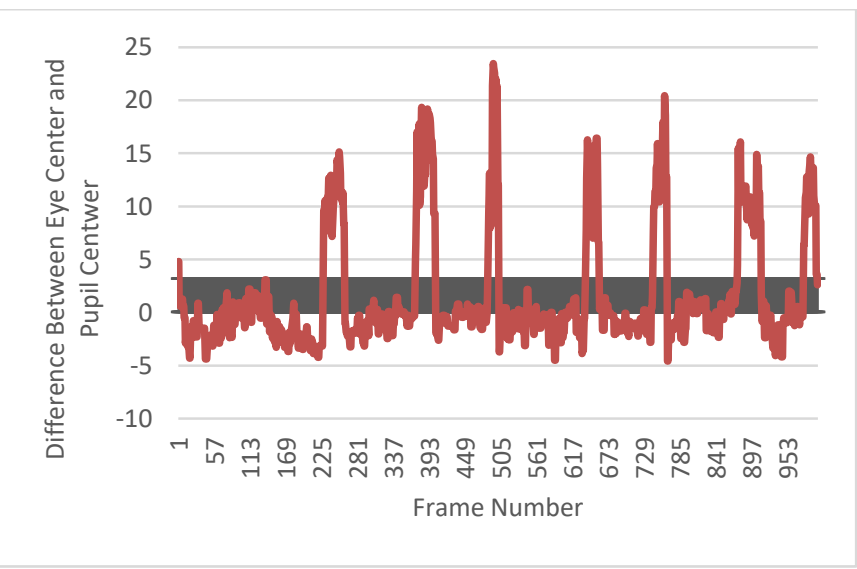

(d) Looking to right, Left eye

Fig. 7. Estimated gaze locations when user is looking to right and left directions.

\section{Evaluation of Probability Density Function of the Difference between Eye Center and Pupil Center}

Probability Density Function: PDF of the difference between eye center and pupil center is evaluated as a function of the distance between user and mobile phone NIR camera. As the result of the experiment, shown in Fig. 8, it is found that shortest distance of $15 \mathrm{~cm}$ shows the best performance in terms of identification if the direction of which the user is looking to.

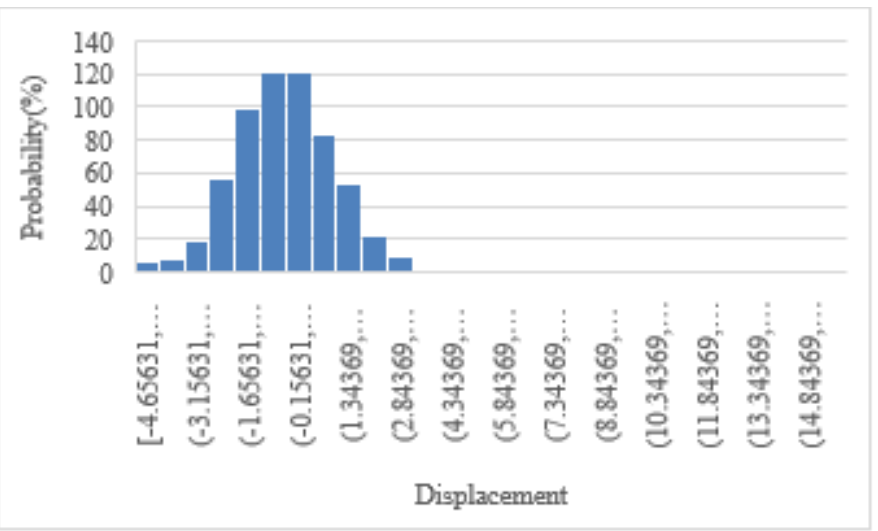

(a) Right eye, $15 \mathrm{~cm}$

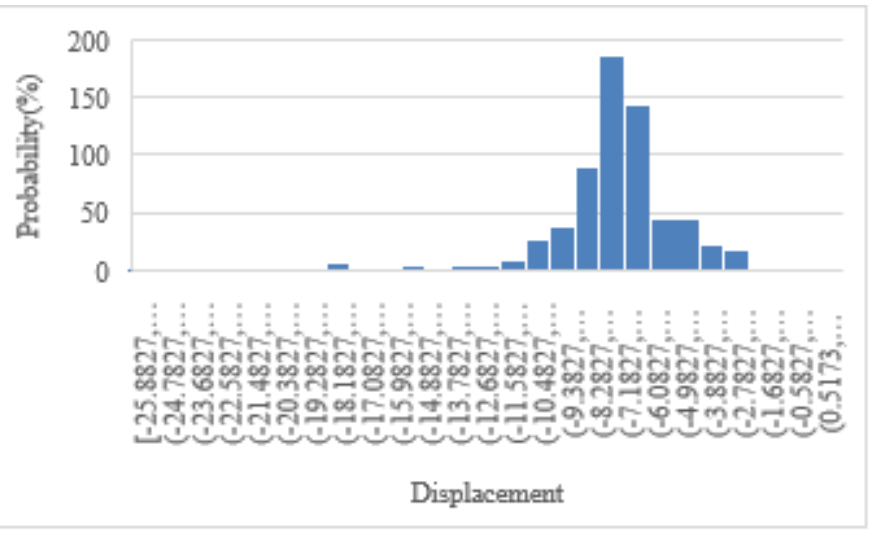

(b) Left eye, $15 \mathrm{~cm}$

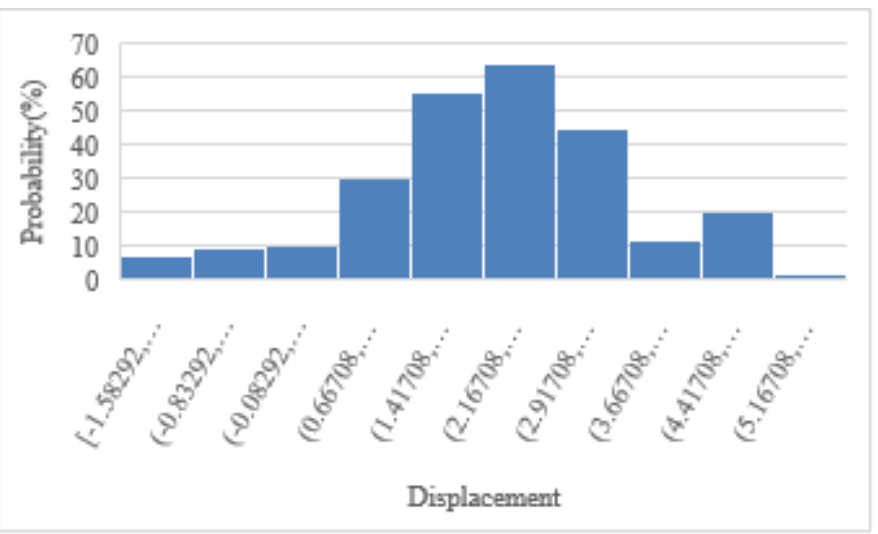

(c) Right eye, $20 \mathrm{~cm}$

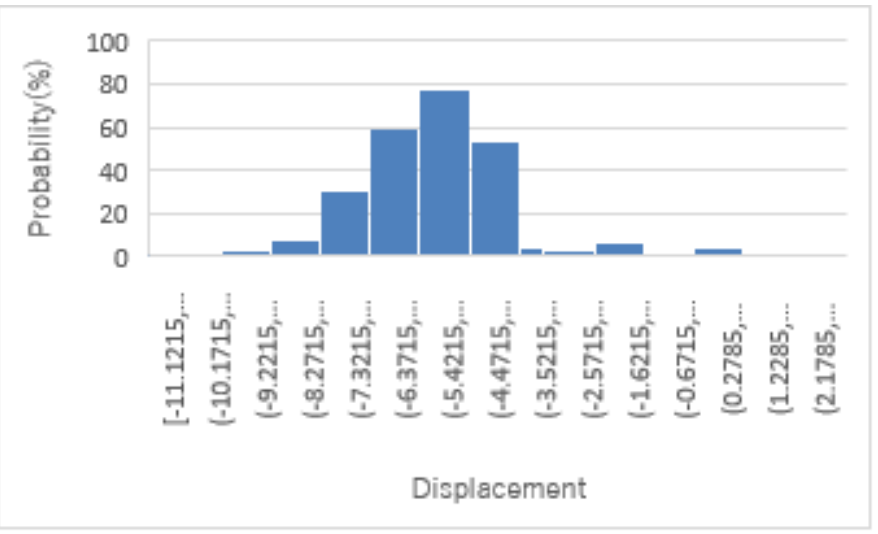

(d) Left eye, $20 \mathrm{~cm}$ 


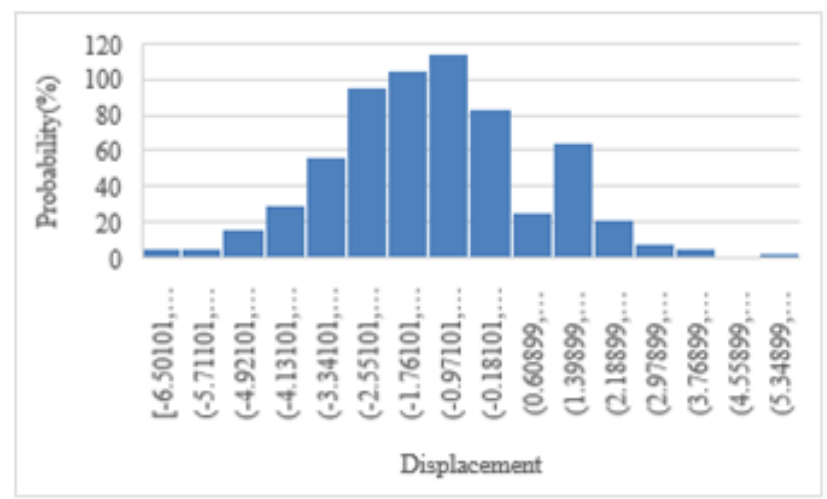

(e) Right eye, $25 \mathrm{~cm}$

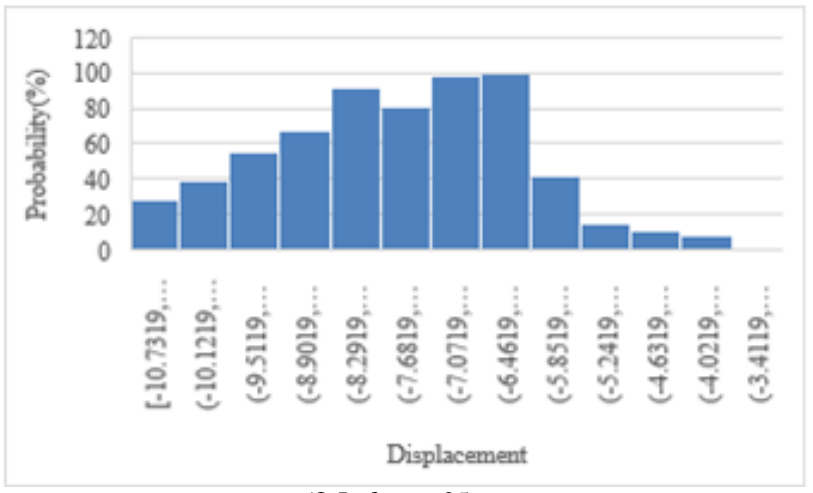

(f) Left eye, $25 \mathrm{~cm}$

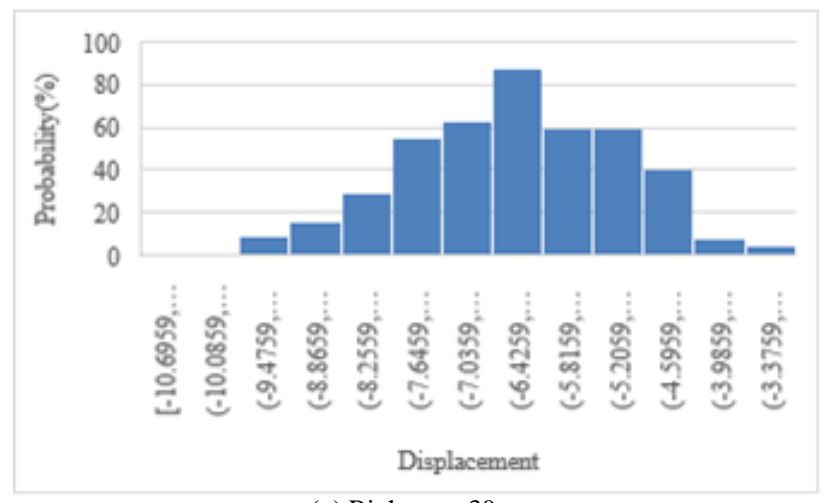

(g) Right eye, $30 \mathrm{~cm}$

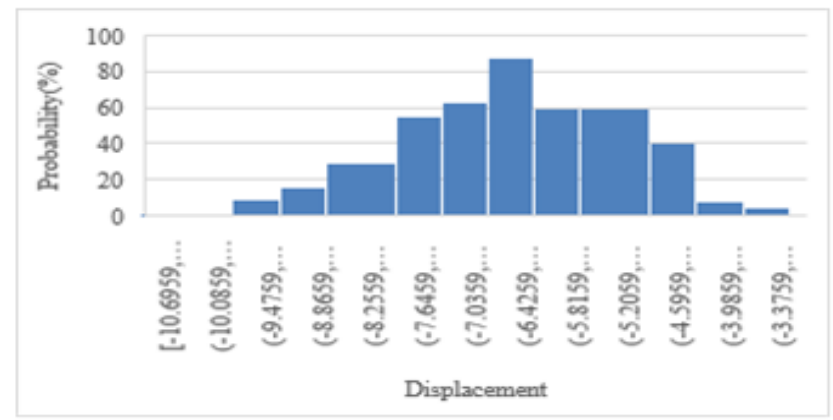

(h) Left eye, $30 \mathrm{~cm}$

Fig. 8. Probability density function of the difference between eye center and pupil center as a function of the distance between user and the NIR camera attached to the mobile phone.

\section{Illumination Condition}

On the other hand, the area and the short radius as well as the long radius of the ellipsoid of which pupil shape is approximated depend on the illumination conditions. Fig. 9(a) shows the area which is determined with the short radius over 2 multiplied by the long radius over 2 of the ellipsoid of which pupil shape multiplied by $\pi$ is approximated for the right eye while those of the left eye is shown in Fig. 9(b), respectively. The grey colored line shows the right eye area for the illumination condition of 1 to 10 Lux, while red colored line shows that of 40 to $50 \mathrm{Lux}$. On the other hand, the blue colored line shows that of 140 to 150 Lux, respectively. Those are same thing for the left eye of the illumination condition. It is obvious that the area and the short radius as well as the long radius of the ellipsoid of which pupil shape is approximated is getting smaller when the brighter illumination condition.

Fig. 10 also shows the estimated short radius and the long radius of the ellipsoid of which the acquired pupil shape is approximated.

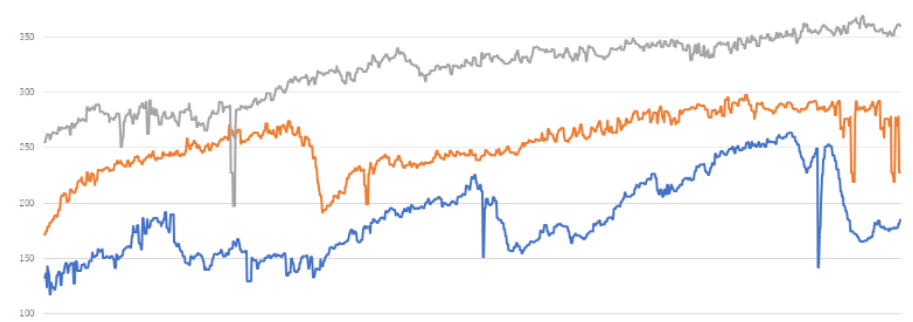

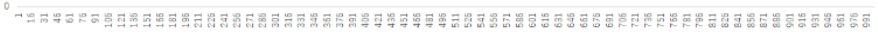

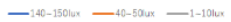

(a) Right eye

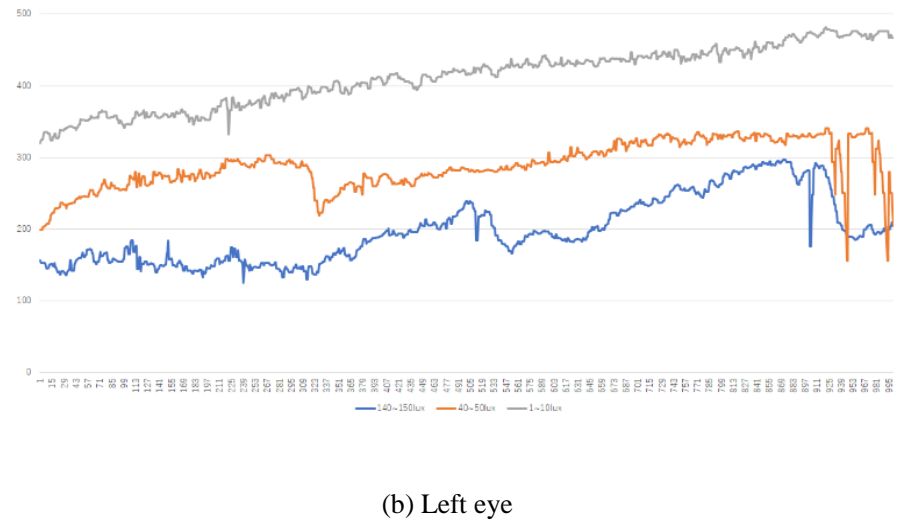

Fig. 9. The calculated area of the detected pupil under the different illumination conditions, 0-10 (grey), 40-50 (orange) and 140-150 (blue) Lux. 


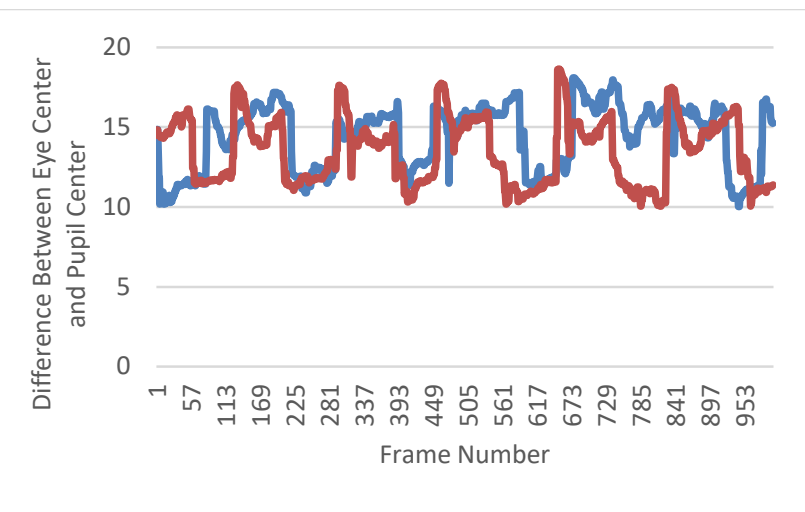

(a) Right direction, Short radius

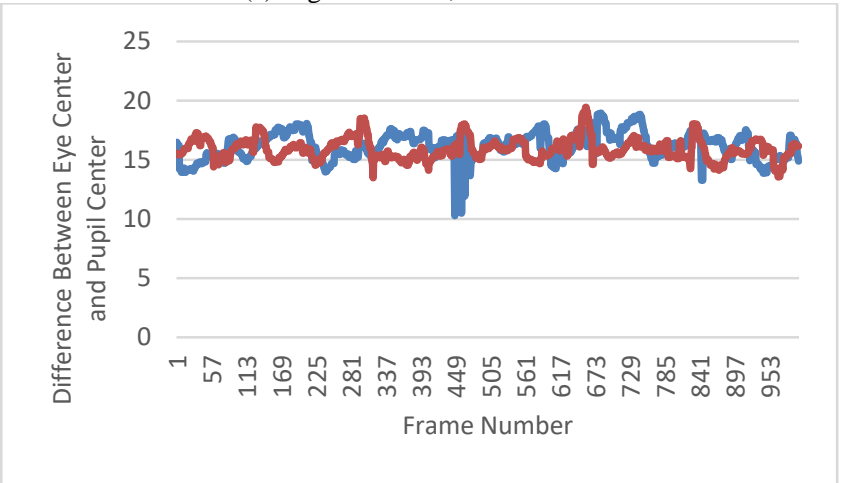

(b) Left direction, Short radius

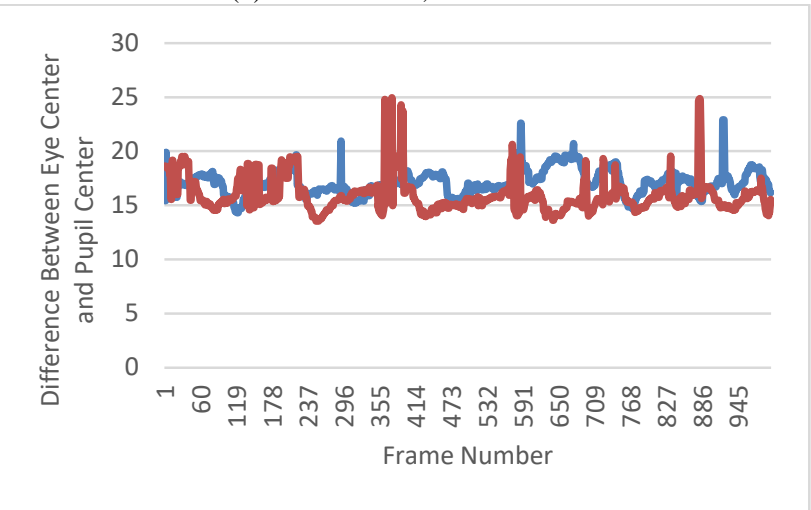

(c) Right direction, Long radius

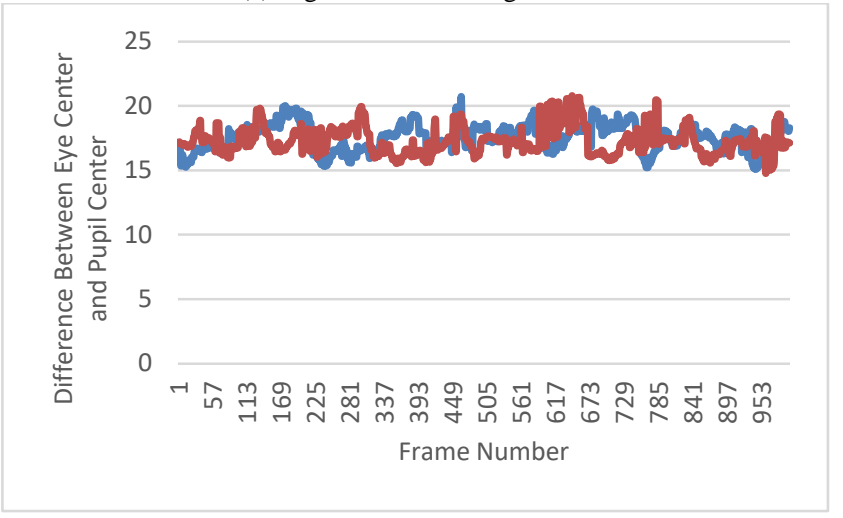

(d) Left direction, Long radius

Fig. 10. Difference between eye center and pupil center of long and short radius when the user is looking to the right and left directions.

\section{EXAMPLES OF APPLICATION}

One of the applications of the proposed system is cocking with referring to a recipe. Fig. 11 shows an example of mobile phone operation with look direction and blink detections for the cocking with referring to the recipe. Without touching to mobile phone, user can use mobile phone operation, page forward, backward, showing the content, as well as the menu for cocking. Users' response is positive for all. Fig. 11(a) shows the start menu (main menu) while Fig. 11(b) shows the sub-menu when the user selected the second recipe from the main menu by using the right eye close (user select the desired downward direction of sub menu).

Another example is construction of houses and buildings with referring to design drawings as well as construction procedures without touching screen of the display of their mobile phone. Constructing workers can refer the documents and drawings when they working at construction sites in a safe manner.
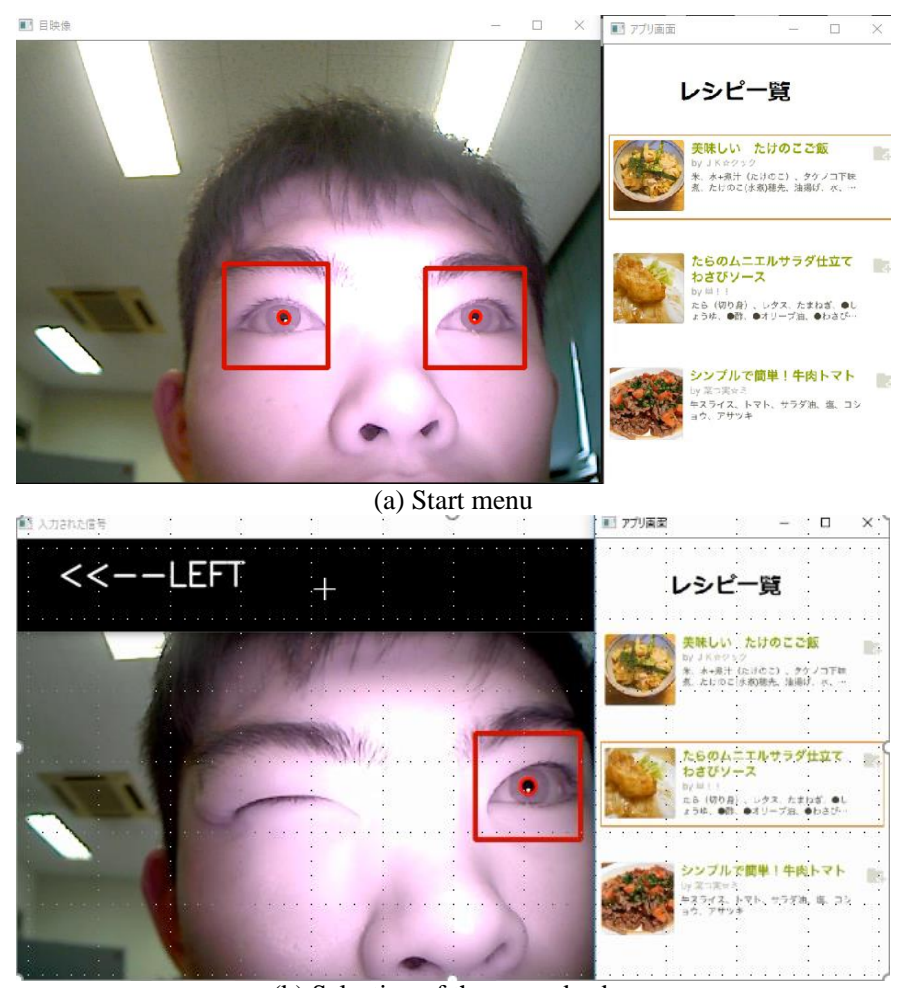

(b) Selection of the second sub menu

Fig. 11. Example of mobile phone operation with look direction and blink detections.

\section{CONCLUSION}

Mobile phone operations using human eyes only are proposed together with its applications for cocking with referring to recipes and manufacturing with referring to manuals, production procedure, and so on. It is found that most of mobile phone operations can be done without touching the screen of the mobile phone. Also, mobile phone operation success rate based on the proposed method is evaluated for the environmental illumination conditions, visible or Near Infrared: NIR cameras, the distance between user and mobile phone, as well as pupil size detection 
accuracy against the environmental illumination changes. Meanwhile, the functionality of two typical applications of the proposed method is confirmed successfully.

Further investigation is required for application of the proposed method and system.

\section{ACKNOWLEDGMENT}

Author would like to thank Mr. Ryuichi Ohmori of Saga University for his cooperation through this research work.

\section{REFERENCES}

[1] Kohei Arai, R.Mardiyanto, Evaluation of users' impact for using the proposed eye based HCI with moving and fixed keyboard by using eeg signals, International Journal of Research and review on Computer Science, 2, 6, 1228-1234, 2012.

[2] Kohei Arai, R.Mardiyanto, Electric wheel chair controlled by human eyes only with obstacle avoidance, International Journal of Research and Review on Computer Science, 2, 6, 1235-1242, 2012.

[3] Kohei Arai, R.Mardiyanto, Robot arm control with human eyes only and its application to help having meal for patients, Journal of Electrical Engineering Society of Japan, Transaction C, C132, 3, 416-423, 2012.

[4] Kohei Arai, Human-Computer Interaction with human eyes only and its applications, Journal of Image Electronics Society of Japan, 41, 3, 296301, 2012.

[5] R.Mardiyanto, Kohei Arai, Eye-based Human Computer Interaction (HCI) A new keyboard for improving accuracy and minimizing fatigue effect, Scientific Journal Kursor, (ISSN 0216-0544), 6, 3, 1-4, 2012.

[6] Kohei Arai, R.Mardiyanto, Moving keyboard for eye-based Human Computer Interaction: HCI, Journal of Image and Electronics Society of Japan, 41, 4, 398-405, 2012.

[7] Kohei Arai, R.Mardiyanto, Service robot which is controlled by human eyes only with voice communication capability, Journal of Image Electronics Society of Japan, 41, 5, 535-542, 2012.

[8] Kohei Arai, Ronny Mardiyanto, Eye-based domestic robot allowing patient to be self-services and communications remotely, International Journal of Advanced Research in Artificial Intelligence, 2, 2, 29-33, 2013.

[9] Kohei Arai, Ronny Mardiaynto, Method for psychological status estimation by gaze location monitoring using eye-based HumanComputer Interaction, International Journal of Advanced Computer Science and Applications, 4, 3, 199-206, 2013.

[10] Kohei Arai, Kiyoshi Hasegawa, Method for psychological status monitoring with line of sight vector changes (Human eyes movements) detected with wearing glass, International Journal of Advanced Research in Artificial Intelligence, 2, 6, 65-70, 2013.

[11] Kohei Arai, Wearable computing system with input output devices based on eye-based Human Computer Interaction: HCI allowing location based web services, International Journal of Advanced Research in Artificial Intelligence, 2, 8, 34-39, 2013.

[12] Kohei Arai Ronny Mardiyanto, Speed and vibration performance as well as obstacle avoidance performance of electric wheel chair controlled by human eyes only, International Journal of Advanced Research in Artificial Intelligence, 3, 1, 8-15, 2014.

[13] Kohei Arai, Service robot with comminunication aid together with routing controlled by human eyes, Journal of Image Laboratory, 25, 6, 24-29, 2014

[14] Kohei Arai, Information collection service system by human eyes for disable persons, Journal of Image Laboratory, 25, 11, 1-7, 2014

[15] Kohei Arai, Relations between psychological status and eye movements, International Journal of Advanced Research on Artificial Intelligence, 4, 6, 16-22, 2015.

[16] Kohei Arai, Method for 3D Image Representation with Reducing the Number of Frames Based on Characteristics of Human Eyes, International Journal of Advanced Research on Artificial Intelligence, 5, 8, 7-12, 2016.

[17] Kohei Arai, Error Analysis of Line of Sight Estimation Using Purkinje Images for Eye-Based Human Computer Interaction: EBHCI, International Journal of Advanced Research on Artificial Intelligence, 5, 10, 14-23, 2016.

[18] Kohei Arai, New service robot controlled by human eye which allows patients in hospitals self-services remotely, Austin Journal of Robotics \& Automation, 3, 1, 1-7, ISSN 2471-0407, 2017.

\section{AUTHOR's PROFILE}

Kohei Arai, He received BS, MS and PhD degrees in 1972, 1974 and 1982, respectively. He was with The Institute for Industrial Science and Technology of the University of Tokyo from April 1974 to December 1978 and also was with National Space Development Agency of Japan from January, 1979 to March, 1990. During from 1985 to 1987, he was with Canada Centre for Remote Sensing as a Post Doctoral Fellow of National Science and Engineering Research Council of Canada. He moved to Saga University as a Professor in Department of Information Science on April 1990. He was a councilor for the Aeronautics and Space related to the Technology Committee of the Ministry of Science and Technology during from 1998 to 2000. He was a councilor of Saga University for 2002 and 2003. He also was an executive councilor for the Remote Sensing Society of Japan for 2003 to 2005. He is an Adjunct Professor of University of Arizona, USA since 1998. $\mathrm{He}$ also is Vice Chairman of the Commission-A of ICSU/COSPAR since 2008. He received Science and Engineering Award of the year 2014 from the minister of the ministry of Science Education of Japan and also received the Best Paper Award of the year 2012 of IJACSA from Science and Information Organization: SAI. In 2016, he also received Vikram Sarabhai Medal of ICSU/COSPAR and also received 37 awards. He wrote 37 books and published 570 journal papers as well as 370 conference papers. He is Editorin-Chief of International Journal of Advanced Computer Science and Applications as well as International Journal of Intelligent Systems and Applications. http://teagis.ip.is.saga-u.ac.jp/ 